\title{
Prevalence of periparturient diseases and effects on fertility of seasonally calving grazing dairy cows supplemented with concentrates
}

\author{
E. S. Ribeiro, F. S. Lima, L. F. Greco, R. S. Bisinotto, A. P. A. Monteiro, M. Favoreto, H. Ayres, R. S. Marsola, \\ N. Martinez, W. W. Thatcher, and J. E. P. Santos ${ }^{1}$ \\ Department of Animal Sciences, University of Florida, Gainesville 32611
}

\section{ABSTRACT}

The objectives were to characterize the prevalence of periparturient diseases and their effects on reproductive performance of dairy cows in seasonal grazing farms. A total of 957 multiparous cows in 2 farms ( 555 in farm A and 402 in farm B) were evaluated and diseases characterized. At calving, dystocia, twin birth, stillbirth, and retained fetal membranes were recorded and grouped as calving problems. On $\mathrm{d} 7 \pm 3$ and $14 \pm 3$ postpartum, cows were evaluated for metritis and on d $28 \pm 3$ for clinical endometritis based on scoring of the vaginal discharge. From parturition to $30 \mathrm{~d}$ after artificial insemination (AI), prevalence of mastitis, lameness, and digestive and respiratory problems were recorded. For subclinical diseases, diagnosis was based on blood samples collected from 771 cows and analyzed for concentrations of $\mathrm{Ca}$, nonesterified fatty acids (NEFA), and $\beta$-hydroxybutyrate. Cows were considered as having elevated NEFA concentration if the concentration was $\geq 0.70 \mathrm{~m} M$, subclinical ketosis if the $\beta$-hydroxybutyrate concentration was $\geq 0.96 \mathrm{~m} M$, and subclinical hypocalcemia if the Ca concentration was $\leq 2.14 \mathrm{mM}$. Ovaries were scanned on $\mathrm{d} 35 \pm 3$ and $49 \pm 3$ postpartum for determination of estrous cyclicity. All cows were enrolled in a timed AI program and inseminated on the first day of the breeding season: on average, $86 \mathrm{~d}$ postpartum. Overall, $37.5 \%$ (359/957) of the cows presented at least 1 clinical disease and $59.0 \%(455 / 771)$ had at least 1 subclinical health problem. Prevalence of individual diseases was $8.5 \%$ for calving problems, $5.3 \%$ for metritis, $15.0 \%$ for clinical endometritis, $13.4 \%$ for subclinical endometritis, $15.3 \%$ for mastitis, $2.5 \%$ for respiratory problems, $4.0 \%$ for digestive problems, $3.2 \%$ for lameness, $20.0 \%$ for elevated NEFA concentration, $35.4 \%$ for subclinical ketosis, and $43.3 \%$ for subclinical hypocalcemia. Clinical and subclinical diseases had additive negative effects on reproduction, delaying resumption of estrous cyclicity and reducing pregnancy

Received November 1, 2012.

Accepted May 14, 2013.

${ }^{1}$ Corresponding author: jepsantos@ufl.edu per AI (P/AI). Occurrence of multiple diseases further reduced reproductive efficiency compared with a single disease. Individually, subclinical hypocalcemia, elevated NEFA concentration, metritis, and respiratory and digestive problems reduced estrous cyclicity by $\mathrm{d}$ 49 postpartum. Elevated NEFA concentration, calving problem, metritis, clinical and subclinical endometritis, and digestive problems reduced $\mathrm{P} / \mathrm{AI}$ on d 65 after $\mathrm{AI}$. Moreover, calving problems and clinical endometritis increased the risk of pregnancy loss between gestation d 30 and 65. Serum concentrations of $\mathrm{Ca}$ and NEFA were negatively correlated, and both were associated with prevalence of uterine diseases. In conclusion, periparturient diseases were highly prevalent in seasonally calving grazing dairies and affected cows had delayed resumption of estrous cyclicity, reduced $\mathrm{P} / \mathrm{AI}$, and increased risk of pregnancy loss.

Key words: dairy cow, disease, grazing, reproduction

\section{INTRODUCTION}

Seasonal calving is often used in grazing dairy farms to maximize pasture nutrient utilization and avoid temporary environmental constrains such as heat stress during early lactation and the breeding period. In this type of dairy production system, reproductive efficiency is essential to obtain a concentrated calving season on a yearly basis (Morton, 2010). Cows must become pregnant in a short and preestablished period of time, which, in many cases, follows a calendar day to begin and end for all cows. To achieve adequate reproductive performance, high submission rate and pregnancy per AI (P/AI) are mandatory (Morton, 2010). Although estrus detection is not perceived by producers as a major constraint for reproductive management in grazing farms (Brownlie et al., 2011), 13 to $48 \%$ of cows are anovular at the beginning of the breeding season, which limits submission to AI after detection of estrus (Rhodes et al., 2003). The adoption of timed AI programs maximizes submission rates, but $\mathrm{P} / \mathrm{AI}$ of anovular cows are still poor (McDougall, 2010; Ribeiro et al., 2011; 2012). Moreover, factors such as extensive loss of BCS and postpartum health problems have been im- 
plicated with extended anovulation period, reduced $\mathrm{P}$ / AI, and greater risk of pregnancy losses (Santos et al., 2009, 2010). Therefore, minimizing health problems, loss of BCS, and anovulation become cornerstones to achieve high reproductive efficiency in dairy herds.

Nutrient intake is of special concern in grazing farms, as the supply by pasture-only diets is often limited, especially when genetics from high-producing cows not selected for production under grazing conditions are used (Bargo et al., 2003; Kolver, 2003). Even when concentrate is supplied, cows of high genetic merit for production increase milk yield without alleviating the extent and duration of negative energy balance and loss of BCS (Pedernera et al., 2008; Lucy et al., 2009) or without improving reproductive performance (Horan et al., 2004). Therefore, even when grazing cows are supplemented with concentrates, loss of BCS in early lactation can be extensive and compromise reproduction.

In confinement herds in North America, the adoption of standardized health programs for diagnosis and treatment of diseases is common (LeBlanc et al., 2006). Cows are typically evaluated daily during the first few weeks postpartum because of the high incidence of health problems in early lactation. The prevalence of clinical and subclinical diseases in highproducing dairy herds is well characterized (Santos et al., 2009; Chapinal et al., 2011) and some authors have suggested that diseases affect more frequently highproducing cows under confinement than cows on grazing farms (Washburn et al., 2002). Diseases have been associated with reduced reproductive performance of cows in confinement (Santos et al., 2010) and in more traditional grazing systems with limited concentrate supplementation such as in New Zealand (McDougall, 2001). The impact of calving problems, anovulation, and loss of BCS have been well characterized in grazing dairy herds (McDougall, 2001; Rhodes et al., 2003; Ribeiro et al., 2011), but limited information is available on the prevalence of subclinical and clinical postpartum diseases and their effects on reproduction of grazing cows in the United States.

Therefore, the objectives of this study were to characterize the prevalence of periparturient clinical and subclinical diseases and their effects on resumption of estrous cyclicity, P/AI, and pregnancy loss of grazing dairy cows of North America supplemented with concentrates and subjected to timed AI on the first day of the breeding season. It was hypothesized that prevalence of clinical and subclinical diseases in the seasonally grazing farms studied would be comparable to values observed in high-producing dairy cows and that diseases would compromise the reproduction of dairy cows.

\section{MATERIALS AND METHODS}

The Institute of Food and Agricultural Sciences at the University of Florida (Gainesville) Animal Care and Use Committee approved all procedures involving cows in this study.

\section{Cows, Pastures, and Management}

The study was conducted in 2 commercial grazing dairy farms located in Florida. Both were fall/winter seasonally calving herds with similar genetics and management practices. The rolling herd average milk production per cow was approximately $6,000 \mathrm{~kg}$. A total of 957 lactating multiparous dairy cows (North American genetics: 255 Holsteins, 88 Jerseys, and 614 crossbreds), 555 in farm A (237 Holsteins, 44 Jerseys, and 274 crossbreeds) and 402 in farm B (18 Holsteins, 44 Jerseys, and 340 crossbreeds), were enrolled. The crossbred cow population was mostly composed of F1 $(50 / 50)$ and F2 (25/75) generations of crossbreeding between Holsteins and Jerseys. Different genetic groups were managed together in a pasture-based system in both herds. Cows were maintained under irrigated pasture paddocks of 2.7 ha and managed in a daily rotational method, allowing a 15-d resting period. Stocking rate for the total area of pasture was approximately 10 cows/ha. The pasture was composed of annual ryegrass (Lolium multiflorum Lam.) during winter and early spring (cool season), and perennial bermudagrass Tifton 85 (Cynodon spp.) during late spring, summer, and fall (warm season). Expected yearly yields of DM per hectare were approximately 3 to $4 \mathrm{t}$ for annual ryegrass and 12 to $15 \mathrm{t}$ for Tifton 85. The typical composition of ryegrass consumed by cows under grazing is 18 to $20 \% \mathrm{CP}$ and 45 to $50 \%$ NDF, whereas consumed Tifton 85 contains 15 to $18 \% \mathrm{CP}$ and 50 to $55 \%$ NDF. Cows were offered 7 to $13 \mathrm{~kg}$ of concentrates/d on an as-fed basis (86 to $88 \% \mathrm{DM}$ ) during and immediately after each milking according to forage availability, which was estimated at the entrance to each paddock using rising plate meters. The concentrate was based on soybean hulls, citrus pulp, whole cottonseed, cottonseed hulls, corn gluten feed, corn meal, soybean meal, molasses, and a mineral-vitamin premix, and designed to contain approximately $15 \% \mathrm{CP}, 4.5 \%$ ether extract, and $28 \%$ NDF. Cows did not receive glucogenic or Ca supplementation postpartum. Cows were milked twice daily throughout the lactation.

\section{Characterization and Diagnosis of Health Problems}

At calving, dystocia characterized by assisted calving, twin birth, stillbirth, and retained placenta char- 
acterized by presence of fetal membranes the day after calving were recorded and grouped as calving problems (Figure 1). Cows were evaluated for metritis on $\mathrm{d} 7$ \pm 3 and $14 \pm 3$ postpartum by transrectal palpation. Metritis was characterized by an enlarged uterus with fetid watery red-brown vaginal discharge (Sheldon et al., 2009). Cows with metritis had rectal temperature measured and those with a temperature $\geq 39.5^{\circ} \mathrm{C}$ were classified as having puerperal metritis. Clinical endometritis was evaluated on d $28 \pm 3$ postpartum by scoring the vaginal mucus using a vaginal mucus collection device (Metricheck; Simcro Ltd., Hamilton, New Zealand). Mucus was scored on a scale from 0 to 5 as described previously by McDougall et al. (2007), and a score $>2$ was considered as clinical endometritis. Subclinical endometritis was evaluated in 1 of the 2 farms (farm $\mathrm{A} ; \mathrm{n}=429$ ) on $\mathrm{d} 49 \pm 3$ postpartum by endometrial cytology using the cytobrush technique (Dubuc et al., 2010). A total of 200 cells were counted in the cytological slide and the proportion of PMNL determined. Subclinical endometritis was characterized when PMNL constituted $>5 \%$ of cells in the smears (Gilbert et al., 2005).

From parturition to d 30 after the first postpartum AI, mastitis, lameness, digestive, and respiratory problems were evaluated for all cows (Figure 1). At every milking, all cows were examined for signs of clinical mastitis by the herd personnel immediately before milking. Clinical mastitis was characterized by the presence of abnormal milk or by signs of inflammation in 1 or more quarters. Digestive problems were characterized by diarrhea, bloat, or displacement of the abomasum. Respiratory problems were characterized by increased respiratory frequency associated with fever and presence of increased lung sounds at auscultation. Cows that stood and walked with arched back and had short strides in 1 or more legs (lameness score $>2$ ) were classified as clinically lame. Except for clinical mastitis and calving problems, all other diseases were diagnosed by veterinarians in the research team.

Blood was sampled from 771 cows on $\mathrm{d} 7 \pm 3$ and $14 \pm 3$ postpartum by puncture of the coccygeal vein or artery (Figure 1) and blood was collected into evacuated tubes with no additives (Vacutainer systems; Becton Dickinson, Franklin Lakes, NJ). Blood tubes were maintained at ambient temperature for $30 \mathrm{~min}$ for clotting and then placed in ice and transported to the laboratory within $5 \mathrm{~h}$ of collection. Tubes were centrifuged at $2,000 \times g$ for $15 \mathrm{~min}$ at $4^{\circ} \mathrm{C}$ for serum separation. Serum samples were frozen at $-20^{\circ} \mathrm{C}$ and later analyzed for concentrations of NEFA, BHBA, and total Ca. Commercial kits were used to determine serum concentrations of NEFA (NEFA-C kit; Wako Diagnostics Inc., Richmond, VA; as modified by Johnson

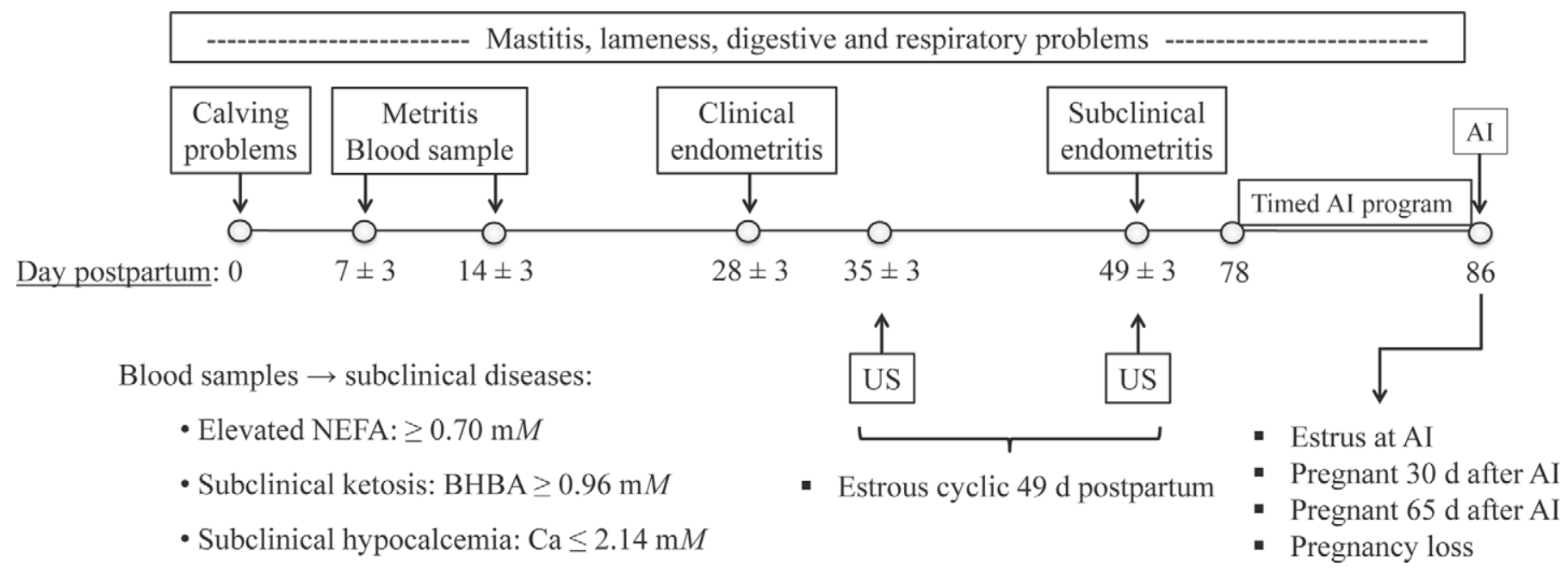

Figure 1. Diagram of activities (closed boxes) and fertility responses evaluated. US $=$ ultrasonography. The timed AI protocol (d 78 GnRH injection, $\mathrm{d} 83$ and $84 \mathrm{PGF}_{2 \alpha}$ injection, and d $86 \mathrm{GnRH}$ injection and $\mathrm{AI}$ ) started when cows averaged $78 \mathrm{~d}$ postpartum and AI was performed when cows averaged $86 \mathrm{~d}$ postpartum. Case definitions were as follows: calving problems = presence of 1 or more of the following: dystocia (assisted calving), twin birth, stillbirth, and retained placenta (retention $>12 \mathrm{~h}$ ); metritis = enlarged uterus with fetid watery red-brown vaginal discharge evaluated on $\mathrm{d} 7 \pm 3$ and $14 \pm 3$ postpartum; clinical endometritis = vaginal mucus score $>2$ (mucopurulent) on d $28 \pm 3$ postpartum; mastitis $=$ abnormal milk or signs of inflammation in 1 or more quarters; digestive problems $=$ diarrhea, bloat, or displacement of abomasum; lameness $=$ cows that walked with arched back and had short strides in 1 or more legs (lameness score $>2$ ); respiratory problems $=$ increased respiratory frequency associated with fever and presence of increased lung sounds at auscultation; subclinical endometritis $=$ endometrial cytology with $>5 \%$ PMNL at $49 \pm 3 \mathrm{~d}$ postpartum; elevated NEFA $=$ serum NEFA concentration $\geq 0.70 \mathrm{~m} M$ on either $\mathrm{d} 7 \pm 3$ or $14 \pm 3$ postpartum; subclinical ketosis $=$ serum BHBA concentration $\geq 0.96 \mathrm{mM}$ on either $\mathrm{d} 7 \pm 3$ or $14 \pm 3$ postpartum; and subclinical hypocalcemia $=$ serum Ca concentration $\leq 2.14 \mathrm{~m} M$ on $\mathrm{d} 7 \pm 3$ postpartum. 
and Peters, 1993) and BHBA (Wako Autokit 3-HB; Wako Diagnostics, Inc.). Concentrations of Ca were determined using an atomic absorption spectrophotometer (AAnalyst 200; Perkin-Elmer Inc., Waltham, MA; Martinez et al., 2012). Cows were considered as having an elevated NEFA concentration if the concentration was $\geq 0.70 \mathrm{~m} M$ and subclinical ketosis if the BHBA concentration was $\geq 0.96 \mathrm{~m} M$ (Ospina et al., 2010) in at least 1 of the 2 samples. Calcium was analyzed only for the first week postpartum $(\mathrm{d} 7 \pm 3)$ and subclinical hypocalcemia was characterized as a concentration of $\mathrm{Ca} \leq 2.14 \mathrm{~m} M$ (Martinez et al., 2012). These cut points were determined in the cited studies (Ospina et al., 2010; Martinez et al., 2012) as the best values to predict increased risk of clinical diseases postpartum. Control serum samples with predetermined high and low concentrations of the analytes were used to evaluate intra- and interassay coefficients of variation. The average intra- and interassay coefficients of variation were 4.8 and $5.2 \%$ for NEFA, 7.1 and $11.5 \%$ for BHBA, and 2.1 and $4.3 \%$ for $\mathrm{Ca}$, respectively.

Retention of fetal membranes, metritis, clinical endometritis, mastitis, lameness, digestive problems, respiratory problems, and death not associated with one of the previously mentioned clinical diseases were all grouped as clinical diseases. Elevated NEFA, subclinical ketosis, and subclinical hypocalcemia were all grouped as subclinical diseases. Subclinical endometritis, as determined in only 1 herd, was not used for categorization of health problems due to the smaller number of cows evaluated $(\mathrm{n}=429)$. Health status of cows was further categorized as healthy, with no diagnosis of disease; a single disease, when a single disease was diagnosed; or multiple diseases when more than 1 disease was diagnosed. These categories were applied 3 times, considering only clinical (all cows; $\mathrm{n}=957$ ), only subclinical (cows in which blood was collected and analyzed; $\mathrm{n}=771$ ), or both health problems (cows in which blood was collected and analyzed; $\mathrm{n}=771$ ). Cows having diagnosis of both clinical and subclinical problems were also classified based on morbidity as healthy, with no clinical or subclinical disease; only subclinical; only clinical; or having both clinical and subclinical diseases. A similar approach was used to categorize cows according to clinical uterine diseases as healthy, only metritis, only clinical endometritis, or having both metritis and clinical endometritis.

\section{Reproductive Management}

All cows were enrolled in a presynchronized timed AI program for first postpartum insemination according to preplanned breeding season (Ribeiro et al., 2011). Cows received 2 injections of $25 \mathrm{mg}$ of $\mathrm{PGF}_{2 \alpha}$ (Lutalyse sterile solution; $5 \mathrm{mg} / \mathrm{mL}$ of dinoprost tromethamine; Zoetis Inc., Madison, NJ) administered $14 \mathrm{~d}$ apart and the timed AI protocol started $10 \mathrm{~d}$ after the second $\mathrm{PGF}_{2 \alpha}$ injection. The timed AI protocol consisted of an injection of $100 \mu \mathrm{g}$ of $\mathrm{GnRH}$ (Cystorelin; $50 \mu \mathrm{g} / \mathrm{mL}$ of gonadorelin diacetate tetrahydrate, Merial Ltd., Iselin, NJ) on d 0 of the protocol, followed by an injection of $\mathrm{PGF}_{2 \alpha}$ on $\mathrm{d} 5$ and 6 , and induction of ovulation with GnRH concurrently with timed AI on d 8. The mean $( \pm \mathrm{SD})$ and median day postpartum at first AI were $86.0( \pm 15.1)$ and 83, respectively. All inseminations were performed from January to March of 2010, when mean monthly daily average temperatures were 11.3, 11.3 , and $14.8^{\circ} \mathrm{C}$, respectively.

\section{Determination of Estrous Cyclicity and Pregnancy Diagnoses}

Ultrasonographic examinations of the ovaries were performed using a $7.5-\mathrm{MHz}$ linear transrectal transducer (Easi-Scan; BCF Technology Ltd., Livingston, UK) for presence of a corpus luteum (CL) on d $35 \pm 3$ and $49 \pm 3$ postpartum. Cows were classified as estrous cyclic on d 49 if a CL was observed in at least 1 of the 2 examinations, or as anovular if no CL was observed in both examinations.

Pregnancy was diagnosed in all cows on d 30 after AI via transrectal ultrasonography of the uterus and its contents and characterized by visualization of a live embryo. Cows diagnosed as pregnant on d 30 were reexamined by transrectal palpation 35 d later. Pregnancy per AI was calculated as the number of pregnant cows on d 30 and 65 after an insemination divided by the total number of cows inseminated. Pregnancy loss was calculated as the number of cows that lost pregnancy between gestation d 30 and 65 divided by the number of pregnant cows on $\mathrm{d} 30$.

\section{BCS and Milk Yield}

Cows were scored for body condition in a 1 to 5 scale (Ferguson et al., 1994) at $7 \pm 3$ and $35 \pm 3 \mathrm{~d}$ postpartum, at $\mathrm{AI}$ and at $30 \mathrm{~d}$ after $\mathrm{AI}$. The BCS at 7 d postpartum was also categorized as $<3.00$, between 3.00 and 3.25 , or $>3.25$ to be used as explanatory variable. Milk yield and concentrations of fat, protein, and lactose were measured by the Southeast DHI laboratory (Gainesville, FL) once during the study when cows averaged 95 d postpartum (range: 46 to 138).

\section{Statistical Analyses}

Binary data were analyzed by logistic regression using PROC GLIMMIX of SAS (version 9.3 SAS/STAT; SAS 
Institute Inc., Cary, NC) fitting binary distribution. Fertility responses of interest were estrous cyclicity on d 49 postpartum, $\mathrm{P} / \mathrm{AI}$ on d 30 and 65 after insemination, and pregnancy loss. Initially, fertility responses were analyzed using a univariable analysis, with each individual clinical and subclinical health problem as single predictor. Predictors from univariable analyses with $P<0.15$ were used to build multivariable logistic regression models for clinical or subclinical health problems. All multivariable logistic regression models included the effects of farm and breed of cow.

To evaluate the effect of clinical diseases on fertility of grazing cows, data were analyzed with multivariable logistic regression, with cows classified as having no disease, a single disease, or multiple diseases. Similarly, to evaluate the effect of subclinical diseases on fertility, data were analyzed with multivariable logistic regression, with cows classified as having no subclinical disease, a single subclinical disease, or multiple subclinical diseases. Additional multivariable analyses were performed, with both clinical and subclinical diseases included in the same models. Cows were classified as healthy when no clinical or subclinical disease was diagnosed, or as having clinical disease only, subclinical disease only, or both clinical and subclinical diseases. Contrasts were performed to determine the effect of disease (healthy vs. all other categories), and the effect of having both clinical and subclinical disease, as opposed to each one of the two individually (clinical and subclinical diseases vs. clinical disease only + subclinical disease only).

For clinical uterine diseases in particular, multivariable logistic regression models were built, with cows classified as having no clinical uterine disease, metritis only, clinical endometritis only, or both metritis and clinical endometritis. Contrasts were performed to determine the effect on clinical uterine disease (no clinical uterine disease vs. all other categories), and the effect of having both metritis and clinical endometritis as opposed to each disease individually (metritis and clinical endometritis vs. metritis only + clinical endometritis only). Because subclinical endometritis was assessed in cows from 1 of the 2 farms, additional statistical analyses were performed to evaluate the effect of subclinical endometritis on fertility responses. Multivariable logistic regression models included prevalence of subclinical endometritis and breed of the cow.

The GLIMMIX procedure of SAS was used for analyses of concentrations of NEFA, BHBA, and Ca in serum; milk yield; and BCS. Concentrations of metabolites and yields of milk were analyzed for each individual disease and categories of clinical and subclinical diseases. Models also included the effects of breed of cow and farm. Analyses were also performed using es- trous cyclicity on d 49, pregnancy on d 30 and 65 after AI, and pregnancy loss as explanatory variables. Days postpartum when production was measured was used for covariate adjustment of data. The BCS at 7 and 35 d postpartum, at AI, and $30 \mathrm{~d}$ after AI were analyzed as repeated measures, with cow within explanatory variable as random effect. Individual diseases and categories of clinical and subclinical diseases were used as explanatory variables and breed of cow and farm as covariates. Body condition at d 7 postpartum was also categorized as $<3.00$, between 3.00 and 3.25 , or $>3.25$, and used as explanatory variable for prevalence of clinical and subclinical diseases. Models included effects of breed of cow and farm.

The CORR procedure of SAS was used to determine Pearson correlation coefficients among serum Ca, NEFA, and BHBA concentrations, BCS on d 7 and 35 postpartum, and BCS change between 7 and $35 \mathrm{~d}$ postpartum. Differences with $P \leq 0.05$ were considered significant and $0.05<P \leq 0.10$ were considered tendencies.

\section{RESULTS}

\section{Prevalence of Clinical and Subclinical Diseases}

Overall, $37.5 \%$ of the cows presented at least 1 clinical health problem and $59.0 \%$ at least 1 subclinical health problem (Table 1). The mean and median days postpartum at diagnosis of the first case of clinical disease were 29.0 and 28.0, respectively. Of the clinical diseases evaluated, clinical endometritis and mastitis were the most prevalent. Of the subclinical diseases evaluated, hypocalcemia was the most prevalent, affecting $43.3 \%$ of the cows in the first $10 \mathrm{~d}$ postpartum. Only $27.0 \%$ of the cows were not diagnosed with either a clinical or subclinical disease postpartum (Table 1). Dystocia, twins, stillborn, and retention of fetal membranes affected, respectively, $1.4,1.8,4.4$, and $3.2 \%$ of the cows in the study, which resulted in $8.5 \%$ of them classified as having calving problems. Metritis affected $5.3 \%$ of the cows, and $52.9 \%$ of them presented hyperthermia and were classified as having puerperal metritis. Subclinical endometritis on d 49 postpartum affected $13.4 \%$ of the cows in the subgroup evaluated in 1 farm.

The prevalence of clinical diseases did not differ $(P=$ $0.29)$ between cows diagnosed with $(34.2 \%)$ or without subclinical diseases (37.8\%). Nonetheless, cows with subclinical hypocalcemia were more likely $(P<0.03)$ to have metritis (4.0 vs. $7.9 \%$ ), subclinical endometritis ( 8.9 vs. $24.1 \%)$ and tended $(P<0.09)$ to be more likely to have clinical endometritis (13.3 vs. $18.1 \%$ ). Additionally, cows with subclinical hypocalcemia were more likely $(P<0.01)$ to be classified as having elevated 
Table 1. Prevalence of clinical and subclinical diseases in early postpartum grazing dairy cows

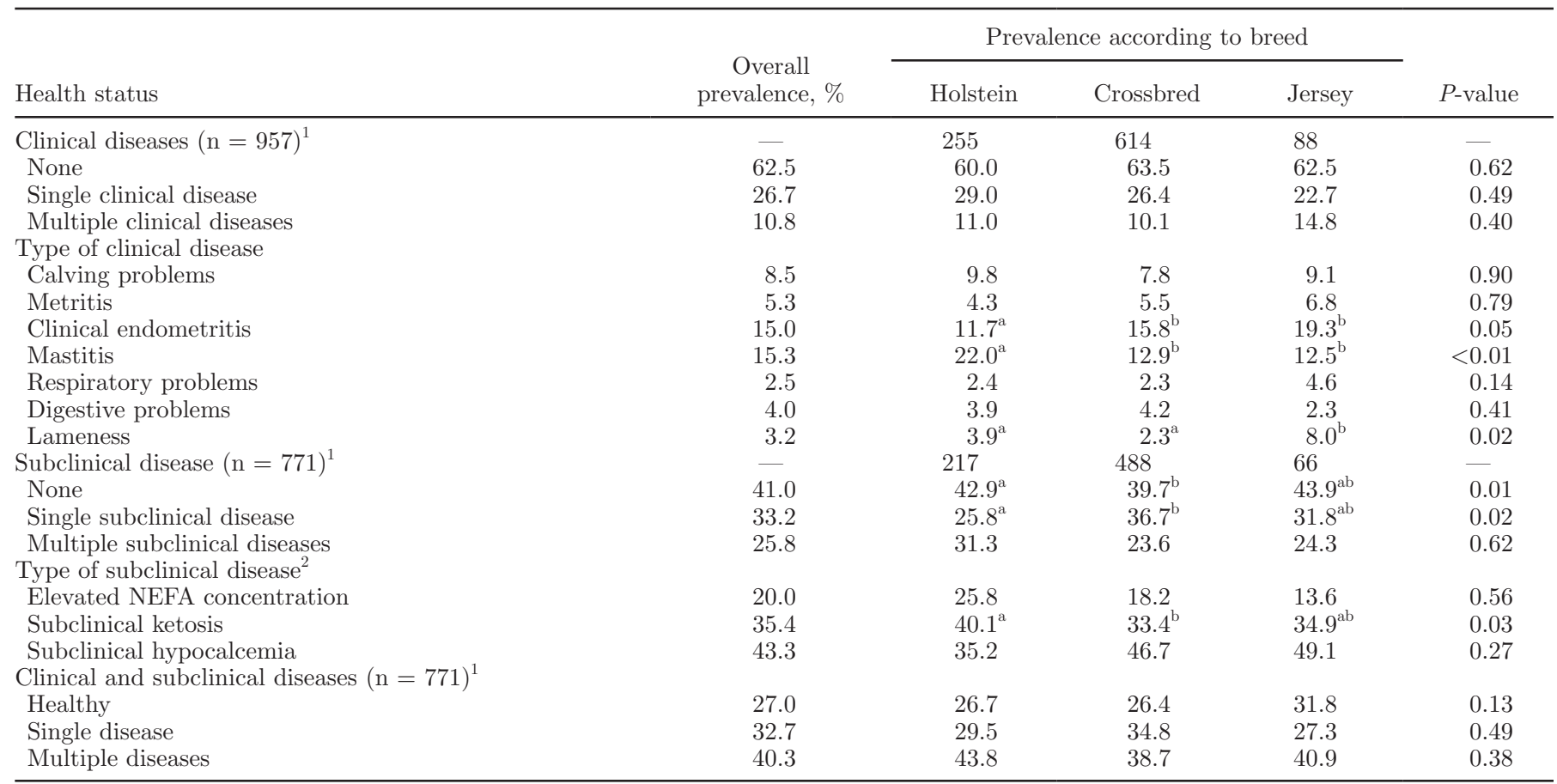

$\overline{\mathrm{a}, \mathrm{b}}$ Different superscripts within the same row indicate significant differences $(P<0.05)$.

${ }^{1} \mathrm{~A}$ total of 957 cows were enrolled in the study and evaluated for prevalence of clinical diseases, and 771 cows had blood sampled and analyzed for concentrations of NEFA, BHBA, and Ca for prevalence of subclinical diseases.

${ }^{2}$ Elevated NEFA concentration $=$ serum NEFA concentration $\geq 0.70 \mathrm{~m} M$; subclinical ketosis was based on a serum BHBA concentration $\geq 0.96$ $\mathrm{m} M$; subclinical hypocalcemia was based on a serum Ca concentration $\leq 2.14 \mathrm{~m} M$.

NEFA concentration (16.2 vs. $27.5 \%)$ and subclinical ketosis (35.3 vs. $41.9 \%)$. Prevalence of calving problems increased $(P<0.01)$ the probability of metritis $(3.0$ vs. $30.9 \%)$ and clinical endometritis (13.4 vs. $34.7 \%)$, and cows with metritis had greater $(P<0.01)$ prevalence of clinical endometritis (12.9 vs. $55.1 \%)$, but not $(P=$ $0.15)$ subclinical endometritis (12.9 vs. $23.8 \%$ ). Cows with clinical endometritis, in turn, were more likely $(P<0.01)$ to have subclinical endometritis $(10.1$ vs. $29.6 \%)$.

Breed of cow did not influence morbidity for clinical diseases (Table 1). Nevertheless, the prevalence of individual health problems differed with breed. Holstein cows had greater $(P<0.01)$ prevalence of twins than crossbred and Jersey cows. Moreover, Holstein cows also had greater $(P<0.01)$ prevalence of mastitis, but smaller $(P=0.05)$ prevalence of clinical endometritis than crossbred and Jersey cows. On the other hand, Jersey cows had greater $(P=0.02)$ prevalence of lameness than Holstein and crossbred cows. For subclinical diseases, crossbred cows had greater $(P<$ $0.01)$ morbidity than Holstein cows (60.3 vs. 57.1\%), and both did not differ $(P=0.22)$ from that of Jersey cows $(56.1 \%)$. Among the subclinical health problems evaluated, breed did not affect the proportion of cows with elevated NEFA concentration or hypocalcemia, but crossbred cows were more likely $(P=0.01)$ to experience subclinical ketosis than Holstein cows, but not Jersey cows. Prevalence of subclinical endometritis did not differ $(P=0.28)$ among breeds.

From calving until first AI, $11.5 \%$ of cows enrolled in the study left the herd either because of death (2.6\%) or culling $(8.9 \%)$. A greater $(P<0.01)$ proportion of cows having clinical disease left the herd than cows not diagnosed with clinical disease (20.6 vs. 6.0\%). Subclinical diseases, however, did not affect $(P=0.72)$ the proportion of cows leaving the herd. Breed of cow did not $(P=0.31)$ influence the proportion of cows leaving the herd before first AI (Holstein: 10.2 vs. crossbred: $12.7 \%$ vs. Jersey: $6.8 \%)$.

\section{Estrous Cyclicity}

Disease influenced estrous cyclicity at $49 \mathrm{~d}$ postpartum (Table 2). Cows considered as healthy were more likely $(P<0.01)$ to be estrous cyclic than cows with at least 1 clinical or subclinical disease. Those cows having both a clinical and subclinical disease had a reduced probability $(P=0.02)$ of being estrous cyclic than cows with either a clinical or subclinical disease 
only (Table 2). When only clinical diseases were considered, estrous cyclicity was reduced $(P<0.01)$ in cows diagnosed with more than 1 health problem, but not in those with a single health problem (Table 3). Among the clinical diseases, those that influenced resumption of estrous cyclicity were metritis and respiratory and digestive problems. When only subclinical diseases were considered, a decrement in the prevalence of estrous cyclicity was observed with increasing number of diseases. Of the subclinical diseases evaluated, estrous cyclicity was reduced $(P<0.01)$ in cows with elevated NEFA concentration and subclinical hypocalcemia. The proportion of estrous cyclic cows tended $(P=0.07)$ to be less for cows with than without subclinical endometritis (81.4 vs. $89.0 \%$ ). Additionally, estrous cyclicity on d 49 postpartum was less $(P<0.01)$ for Holstein than crossbred cows, with no difference between Jerseys and the other 2 breeds (Holstein: $83.1 \%$ vs. crossbred: $91.7 \%$ vs. Jersey: $88.5 \%$ ).

\section{P/AI and Pregnancy Loss}

Sixty-two percent of the cows were pregnant on $\mathrm{d}$ 30 after AI, and this proportion decreased to $54.7 \%$ on d 65 after AI. Anovular cows on d 49 postpartum had smaller $(P<0.001) \mathrm{P} / \mathrm{AI}$ on d $30(36.8$ vs. $64.9 \%)$ and 65 (33.7 vs. $57.1 \%)$ after AI than estrous cyclic counterparts. Breed had no effect $(P=0.30)$ on P/AI.
On d 65 after insemination, $48.6 \%$ of Holsteins, $55.9 \%$ of crossbreds, and $53.0 \%$ of Jerseys were pregnant.

Healthy cows had greater $(P<0.01) \mathrm{P} / \mathrm{AI}$ on $\mathrm{d} 30$ and 65 after insemination than cows diagnosed with diseases (Table 2). A tendency $(P=0.10)$ for a further reduction in $\mathrm{P} / \mathrm{AI}$ on d 30 was observed when cows had clinical and subclinical diseases diagnosed compared with only subclinical or only clinical disease (Table 2). When only clinical disease was considered, then $\mathrm{P} / \mathrm{AI}$ on d 30 and 65 suffered decrements $(P<0.01)$ with increasing number of diseases (Tables 4 and 5 ). Among clinical diseases that affected $(P<0.05) \mathrm{P} / \mathrm{AI}$ on $\mathrm{d} 30$ were metritis and digestive problems. On d 65 after insemination, calving problems, metritis, clinical endometritis, and digestive problems all reduced $(P<0.05)$ $\mathrm{P} / \mathrm{AI}$. When only subclinical disease was considered, $\mathrm{P} / \mathrm{AI}$ on $\mathrm{d} 30$ and 65 were reduced $(P<0.01)$ only in cows diagnosed with more than 1 disease (Tables 4 and $5)$. Of the subclinical diseases, only elevated NEFA was associated with reduced $(P<0.01) \mathrm{P} / \mathrm{AI}$.

Approximately $10.9 \%$ of the pregnant cows lost pregnancy by $65 \mathrm{~d}$ of gestation. Healthy cows had numerically less pregnancy loss than those diagnosed with diseases (Table 2). Nevertheless, when only clinical disease was considered, those with diagnosis of multiple diseases had greater $(P<0.01)$ pregnancy loss than cows with none or a single clinical disease (Table 6). Calving problems and clinical endometritis increased $(P<0.02)$

Table 2. Effect of clinical and (or) subclinical diseases on estrous cyclicity on d 49 postpartum, pregnancy per AI on d 30 and 65 after insemination, and pregnancy loss

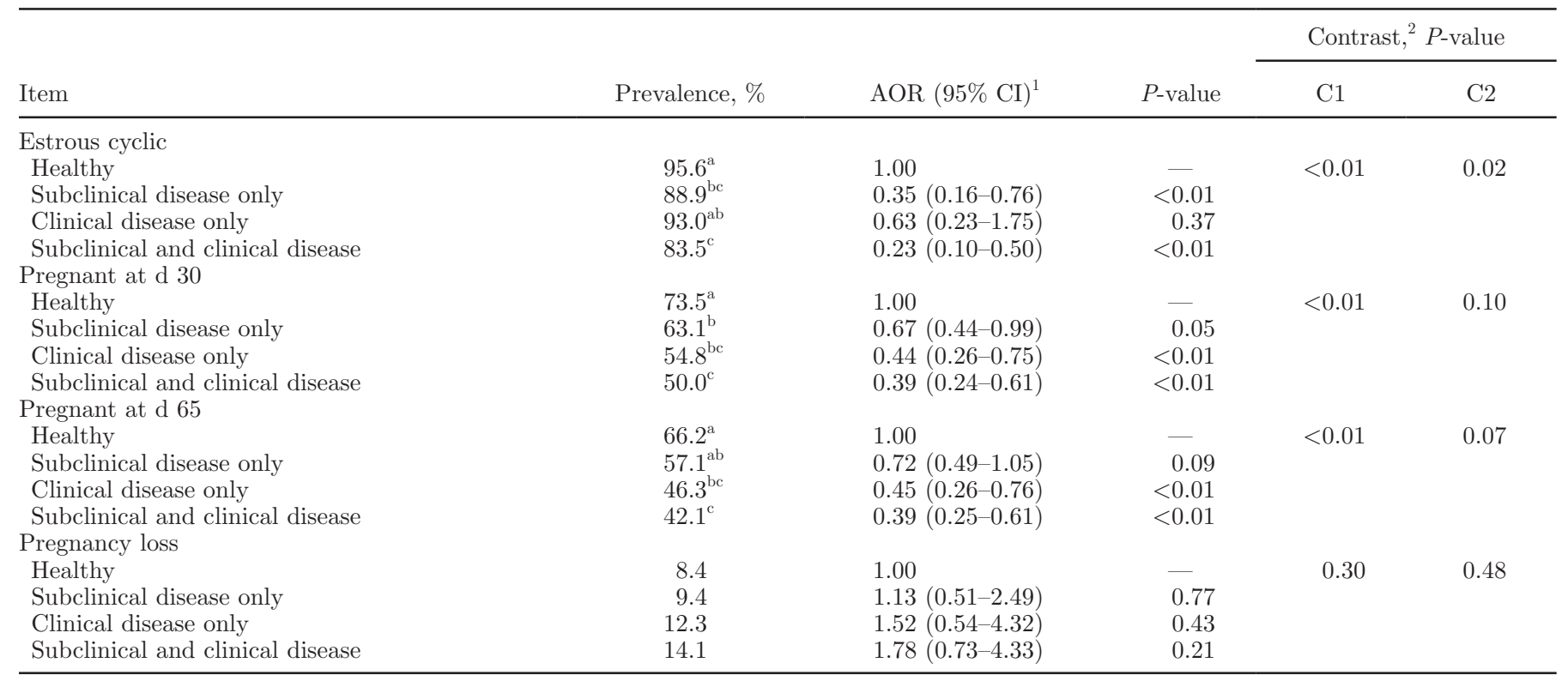

\footnotetext{
${ }^{a-c}$ Different superscripts within a dependent variable indicate significant differences $(P<0.05)$.

${ }^{1} \mathrm{AOR}=$ adjusted odds ratio.

${ }^{2}$ Contrasts: $\mathrm{C} 1=$ effect of disease (healthy vs. all others); C2 = effect of having both clinical and subclinical diseases combined versus only clinical or subclinical (subclinical and clinical disease vs. subclinical disease only + clinical disease only).
} 
Table 3. Effect of postpartum diseases on resumption of estrous cyclicity by d 49 postpartum

\begin{tabular}{|c|c|c|c|c|c|}
\hline Health problem & Cyclic, \% & \multicolumn{2}{|c|}{ Univariable analysis } & \multicolumn{2}{|c|}{ Multivariable analysis ${ }^{1}$} \\
\hline \multicolumn{6}{|l|}{ Clinical disease } \\
\hline Single clinical disease & 88.3 & $0.74(0.45-1.20)$ & 0.22 & $0.75(0.46-1.22)$ & 0.25 \\
\hline Multiple clinical diseases & 77.8 & $0.34(0.19-0.61)$ & $<0.01$ & $0.35(0.20-0.62)$ & $<0.01$ \\
\hline \multicolumn{6}{|l|}{ Type of clinical disease ${ }^{4}$} \\
\hline Mastitis & 88.3 & $0.92(0.52-1.62)$ & 0.77 & - & - \\
\hline Respiratory problems & 63.6 & $0.20(0.08-0.49)$ & $<0.01$ & $0.21(0.08-0.55)$ & $<0.01$ \\
\hline Digestive problems & 62.9 & $0.19(0.09-0.38)$ & $<0.01$ & $0.19(0.09-0.40)$ & $<0.01$ \\
\hline Lameness & 79.3 & $0.46(0.18-1.15)$ & 0.10 & $0.71(0.26-1.97)$ & 0.51 \\
\hline \multicolumn{6}{|l|}{ Subclinical disease } \\
\hline None & 94.8 & 1.00 & - & 1.00 & - \\
\hline Subclinical hypocalcemia & 84.6 & $0.40(0.24-0.67)$ & $<0.01$ & $0.39(0.23-0.67)$ & $<0.01$ \\
\hline
\end{tabular}

${ }^{1}$ Multivariable analysis included effects of farm and breed. For individual diseases, the multivariable model included only diseases that had $P \leq$ 0.10 at the univariable analysis.

${ }^{2} \mathrm{OR}=$ odds ratio.

${ }^{3} \mathrm{AOR}=$ adjusted OR.

${ }^{4}$ Compared with cows not diagnosed with the respective health problem.

${ }^{5}$ Elevated NEFA concentration $=$ serum NEFA concentration $\geq 0.70 \mathrm{~m} M$; subclinical ketosis was based on a serum BHBA concentration $\geq 0.96$ $\mathrm{m} M$; subclinical hypocalcemia was based on a serum Ca concentration $\leq 2.14 \mathrm{~m} M$.

Table 4. Effect of postpartum diseases on pregnancy per AI on d 30 after first insemination

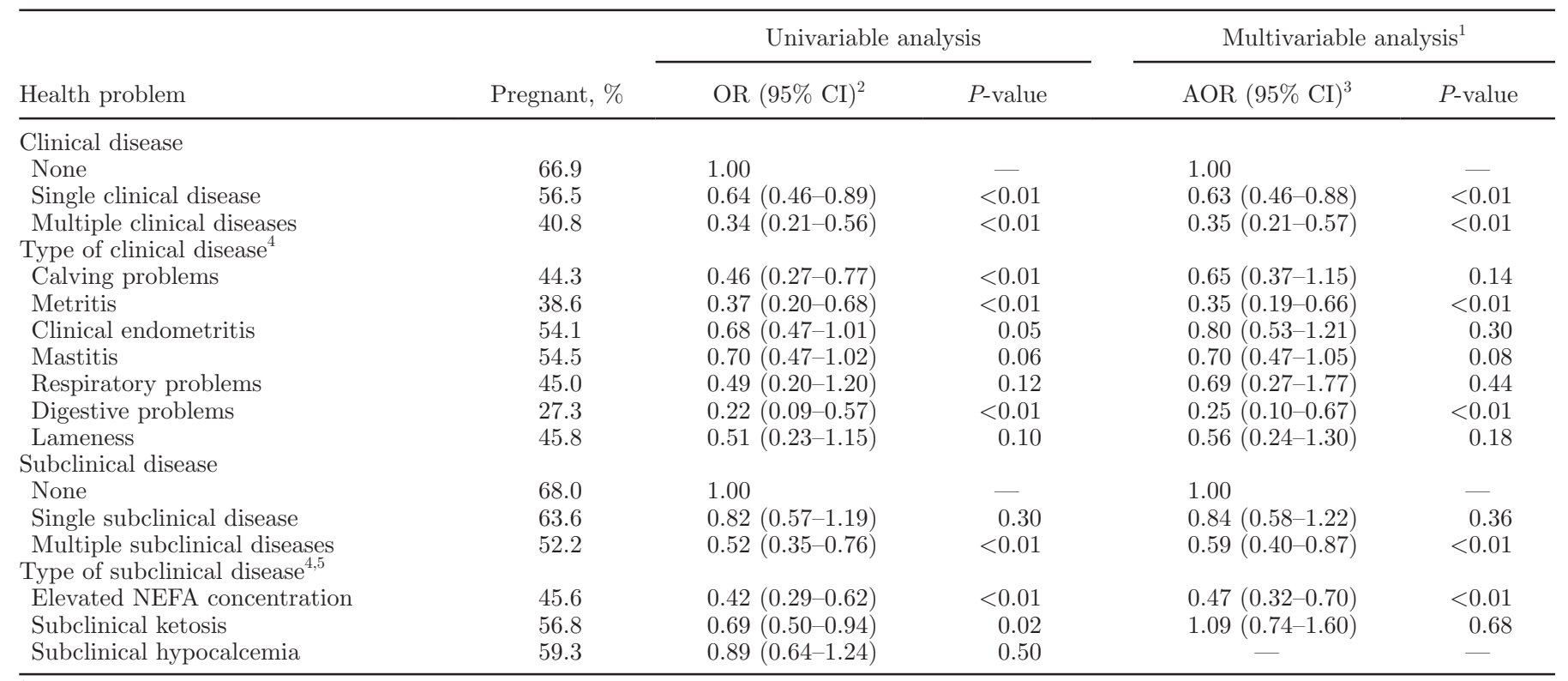

${ }^{1}$ Multivariable analysis included effects of farm and breed. For individual diseases, the multivariable model included only diseases that had $P \leq$ 0.10 at the univariable analysis.

${ }^{2} \mathrm{OR}=$ odds ratio

${ }^{3} \mathrm{AOR}=$ adjusted $\mathrm{OR}$.

${ }^{4}$ Compared with cows not diagnosed with the respective health problem.

${ }^{5}$ Elevated NEFA concentration $=$ serum NEFA concentration $\geq 0.70 \mathrm{~m} M$; subclinical ketosis was based on a serum BHBA concentration $\geq 0.96$ $\mathrm{m} M$; subclinical hypocalcemia was based on a serum Ca concentration $\leq 2.14 \mathrm{~m} M$. 
Table 5. Effect of postpartum diseases on pregnancy per AI on d 65 after first insemination

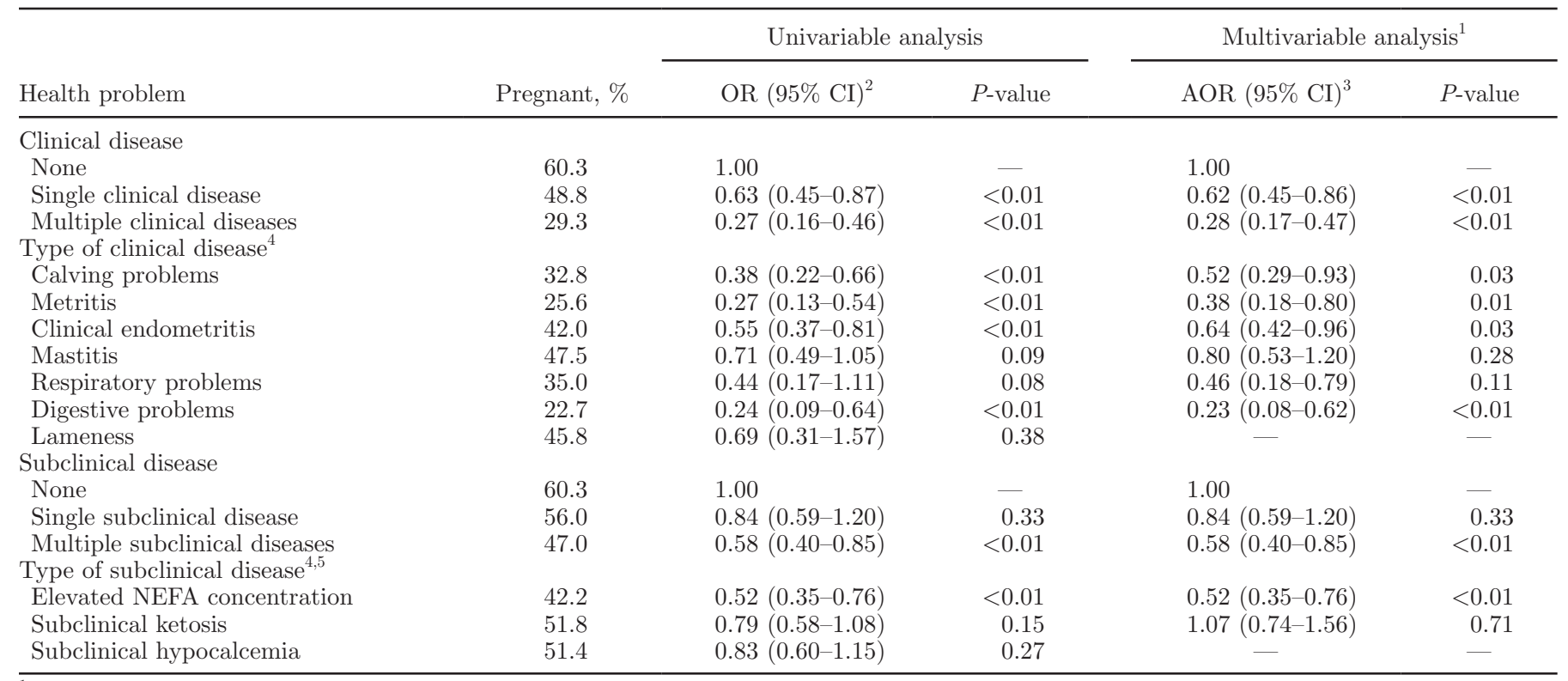

${ }^{1}$ Multivariable analysis included effects of farm and breed. For individual diseases, the multivariable model included only diseases that had $P \leq$ 0.10 at the univariable analysis.

${ }^{2} \mathrm{OR}=$ odds ratio

${ }^{3} \mathrm{AOR}=$ adjusted $\mathrm{OR}$.

${ }^{4}$ Compared with cows not diagnosed with the respective health problem.

${ }^{5}$ Elevated NEFA concentration $=$ serum NEFA concentration $\geq 0.70 \mathrm{~m} M$; subclinical ketosis was based on a serum BHBA concentration $\geq 0.96$ $\mathrm{m} M$; subclinical hypocalcemia was based on a serum Ca concentration $\leq 2.14 \mathrm{~m} M$.

pregnancy loss. No association was observed between subclinical disease and pregnancy loss. Breed of cows did not influence $(P=0.72)$ pregnancy loss, with $11.2 \%$ of Holsteins, $10.9 \%$ of crossbreds, and $10.6 \%$ of Jerseys losing their pregnancies between 30 and $65 \mathrm{~d}$ after AI.

\section{Uterine Diseases and Fertility}

Cows with no clinical uterine disease tended $(P=$ 0.07 ) to be more likely to be cyclic by d 49 postpartum than those with uterine diseases ( 89.4 vs. $86.5 \%$ ), particularly those with metritis or metritis and clinical endometritis combined (77.3\%; Table 7). Pregnancies per AI on d 30 and 65 after insemination were greater $(P<0.01)$ in cows with no uterine disease than those with uterine disease. On d 30, P/AI was $63.9 \%$ for cows without uterine disease compared with $52.4 \%$ for those with clinical uterine disease. On d $65, \mathrm{P} / \mathrm{AI}$ was $57.6 \%$ for cows without uterine disease compared with $40.7 \%$ for those with clinical uterine disease. In fact, P/AI on d 65 was depressed by all types of uterine disease, and an additive effect decreasing $(P<0.05)$ fertility was observed when cows were diagnosed with both metritis and clinical endometritis. A large portion of this decline in fertility caused by uterine diseases was because the latter also increased $(P=0.05)$ the risk of pregnancy loss between 30 and $65 \mathrm{~d}$ of gestation (9.1 vs. $21.9 \%$;
Table 7). Subclinical endometritis reduced $(P<0.03)$ $\mathrm{P} / \mathrm{AI}$ on d 30 (43.6 vs. $59.0 \%)$ and 65 (36.4 vs. $52.9 \%)$ after AI, but did not affect $(P=0.29)$ pregnancy loss (16.7 vs. $10.0 \%)$.

\section{Concentrations of $\mathrm{Ca}, \mathrm{NEFA}$, and BHBA in Serum of Grazing Cows}

Concentrations of $\mathrm{Ca}$ in serum were less $(P<0.04)$ in cows with metritis, clinical endometritis, or subclinical endometritis than those without the respective uterine diseases (Table 8). Additionally, cows with elevated NEFA concentration or subclinical ketosis had lower $(P$ $<0.01)$ Ca concentrations than those without the respective subclinical diseases. Concentrations of NEFA in serum were greater $(P<0.02)$ for cows with metritis, subclinical endometritis, ketosis, and subclinical hypocalcemia than for those without those diseases. Cows with calving problems and those with lameness had smaller $(P<0.01)$ concentrations of BHBA than their herdmates without those clinical diseases; however, cows with elevated NEFA concentration and subclinical hypocalcemia had increased $(P<0.05)$ concentrations of BHBA in serum.

Calcium was negatively correlated with NEFA ( $\mathrm{r}=$ $-0.17 ; P<0.01)$ and BHBA $(\mathrm{r}=-0.07 ; P=0.07)$, and positively correlated with BCS on $\mathrm{d} 7(\mathrm{r}=0.16 ; P<$ 
Table 6. Effect of postpartum diseases on pregnancy loss between gestational d 30 and 65

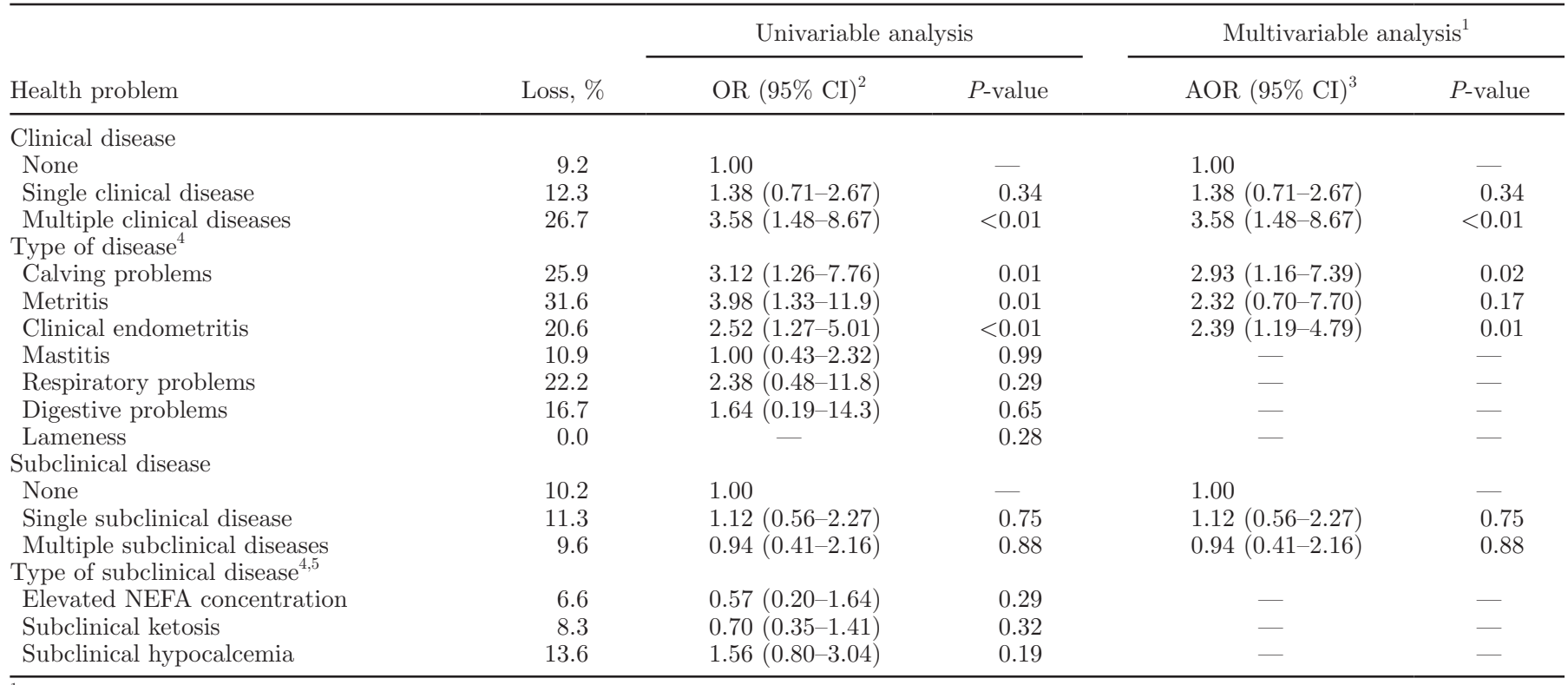

${ }^{1}$ Multivariable analysis included effects of farm and breed. For individual diseases, the multivariable model included only diseases that had $P \leq$ 0.10 at the univariable analysis.

${ }^{2} \mathrm{OR}=$ odds ratio.

${ }^{3} \mathrm{AOR}=$ adjusted OR.

${ }^{4}$ Compared with cows not diagnosed with the respective health problem.

${ }^{5}$ Elevated NEFA concentration $=$ serum NEFA concentration $\geq 0.70 \mathrm{~m} M$; subclinical ketosis was based on a serum BHBA concentration $\geq 0.96$ $\mathrm{m} M$; subclinical hypocalcemia was based on a serum Ca concentration $\leq 2.14 \mathrm{~m} M$.

Table 7. Effect of clinical uterine diseases on estrous cyclicity on d 49 postpartum, pregnancy per AI on d 30 and 65 after insemination, and pregnancy loss

\begin{tabular}{|c|c|c|c|c|c|}
\hline Item & Prevalence, \% & $\operatorname{AOR}(95 \% \mathrm{CI})^{1}$ & $P$-value & \multicolumn{2}{|c|}{ Contrast, ${ }^{2} P$-value } \\
\hline \multicolumn{6}{|l|}{ Estrous cyclic } \\
\hline Clinical endometritis only & 90.7 & $1.18(0.59-2.38)$ & 0.63 & \multirow{3}{*}{0.07} & \multirow{3}{*}{0.38} \\
\hline Metritis only & 77.2 & $0.41(0.15-1.17)$ & 0.09 & & \\
\hline Metritis and clinical endometritis & 77.4 & $0.42(0.15-1.16)$ & 0.09 & & \\
\hline Clinical endometritis only & $58.6^{\mathrm{ab}}$ & $0.82(0.53-1.27)$ & 0.38 & \multirow{3}{*}{$<0.01$} & \multirow{3}{*}{0.12} \\
\hline Metritis only & $42.9^{\mathrm{bc}}$ & $0.43(0.18-1.03)$ & 0.06 & & \\
\hline Metritis and clinical endometritis & $37.5^{\mathrm{c}}$ & $0.32(0.14-0.74)$ & $<0.01$ & & \\
\hline \multicolumn{6}{|l|}{ Pregnant at d 65} \\
\hline No uterine disease & $57.6^{\mathrm{a}}$ & 1.00 & - & \multirow[t]{3}{*}{$<0.01$} & \multirow[t]{3}{*}{0.05} \\
\hline Clinical endometritis only & $47.2^{\mathrm{b}}$ & $0.68(0.44-1.04)$ & 0.07 & & \\
\hline Metritis only & $33.3^{\mathrm{bc}}$ & $0.37(0.15-0.93)$ & 0.03 & & \\
\hline \multicolumn{6}{|l|}{ Pregnancy loss } \\
\hline Metritis and clinical endometritis & $42.9^{\mathrm{c}}$ & $7.33(1.57-34.12)$ & 0.01 & $<0.01$ & 0.25 \\
\hline
\end{tabular}

\footnotetext{
${ }^{\mathrm{a}-\mathrm{c}}$ Different superscripts within a dependent variable indicate significant differences $(P<0.07)$.

${ }^{1} \mathrm{AOR}=$ adjusted odds ratio.

${ }^{2}$ Contrasts: $\mathrm{C} 1=$ effect of uterine disease (no uterine disease vs. all others); $\mathrm{C} 2=$ effect of having both metritis and clinical endometritis combined versus only metritis or clinical endometritis (metritis and clinical endometritis vs. clinical endometritis only + metritis only).
} 
$0.01)$ and $35(\mathrm{r}=0.19 ; P<0.01)$. Moreover, NEFA was positively correlated with BHBA $(\mathrm{r}=0.56 ; P<0.01)$ and BCS on $\mathrm{d} 7(\mathrm{r}=0.20 ; P<0.01)$, but negatively correlated with BCS on $\mathrm{d} 35(\mathrm{r}=-0.12 ; P<0.01)$ and change in BCS $(\mathrm{r}=-0.32 ; P<0.01)$. The serum NEFA concentrations decreased as the BCS change went from loss to gain in body condition. Similarly, BHBA was also positively correlated with BCS on d $7(\mathrm{r}=0.19 ; P$ $<0.01)$, and negatively correlated with BCS on d 35 (r $=-0.08 ; P=0.04)$ and change in BCS $(\mathrm{r}=-0.28 ; P<$ 0.01). The serum BHBA concentrations also decreased as the change in BCS went from loss to gain in body condition.

Cows that were estrous cyclic on d 49 postpartum had greater $(P<0.01)$ concentrations of $\mathrm{Ca}$ and smaller $(P=0.02)$ concentrations of NEFA in serum than anovular cows (Table 9). Concentrations of NEFA and BHBA were smaller $(P<0.05)$ for pregnant than nonpregnant cows. Nevertheless, concentrations of $\mathrm{Ca}$, NEFA, and BHBA did not differ among pregnant cows that maintained or lost their pregnancy in the first 65 $\mathrm{d}$ of gestation.

\section{BCS and Milk Yield}

The body condition was affected $(P<0.01)$ by breed, day of measurement, and their interaction. At $7 \mathrm{~d}$ postpartum, Holstein cows had higher $(P=0.02)$ BCS than Jerseys, and tended $(P=0.09)$ to have higher BCS than crossbreds $(3.07 \pm 0.02$ vs. $2.96 \pm 0.04$ vs. $3.02 \pm 0.01$, respectively). Nonetheless, crossbred cows had higher $(P=0.03)$ BCS at $35 \mathrm{~d}$ postpartum than Holsteins, and both did not differ $(P>0.17)$ from Jerseys $(2.97 \pm 0.01$ vs. $2.92 \pm 0.02$ vs. $2.92 \pm 0.03$, respectively). At AI, BCS differed $(P<0.01)$ among all 3 groups, and it was higher for crossbreds, followed by Jerseys and Holsteins $(3.04 \pm 0.01$ vs. $2.93 \pm 0.03$ vs. $2.83 \pm 0.02$, respectively). At $30 \mathrm{~d}$ after AI, crossbred cows had higher $(P<0.01)$ BCS than Holstein and Jerseys cows $(3.14 \pm 0.02,2.92 \pm 0.03$, and $2.93 \pm 0.04$, respectively).

Cows with clinical diseases had lower BCS $(P<0.02)$ than cows without clinical diseases at all 4 time points evaluated and it averaged $2.94 \pm 0.02$ and $3.00 \pm 0.01$, respectively (Figure 2A). No difference was observed in BCS between cows with a single clinical disease and those with multiple clinical diseases. The mean BCS was less $(P<0.05)$ at all 4 time points for cows with digestive problems, from $35 \mathrm{~d}$ postpartum for cows with respiratory problems, and from AI for cows with lameness. Other clinical diseases were not associated with BCS.

Cows with subclinical diseases had higher $(P=0.05)$ $\mathrm{BCS}$ at $7 \mathrm{~d}$ postpartum than cows without subclinical diseases $(3.03 \pm 0.02$ vs. $2.98 \pm 0.02$; Figure $2 B)$. Nevertheless, cows with subclinical diseases lost more $(P<$ $0.01)$ BCS between 7 and $35 \mathrm{~d}$ postpartum, which resulted in smaller BCS throughout the remainder of the study compared with cows without subclinical diseases (Figure 2B). Cows with subclinical hypocalcemia had lower $(P<0.01)$ BCS than cows with normocalcemia throughout the study, averaging $2.94 \pm 0.02$ and 3.01 \pm 0.02 , respectively (Figure $2 \mathrm{C}$ ). On the other hand, cows with elevated NEFA concentration had higher $(P$ $<0.01)$ BCS at $7 \mathrm{~d}$ postpartum $(3.13 \pm 0.03$ vs. 2.98 \pm 0.02 ), but because of greater losses until AI, they had smaller BCS at AI and $30 \mathrm{~d}$ after AI (Figure 2D). Similarly, cows with subclinical ketosis had higher $(P$ $<0.01)$ BCS at $7 \mathrm{~d}$ postpartum $(3.11 \pm 0.02$ vs. $2.95 \pm$ $0.02)$, but smaller $(P<0.01)$ BCS at AI $(2.85 \pm 0.02$ vs. $3.01 \pm 0.02)$ and $30 \mathrm{~d}$ after $\mathrm{AI}(2.93 \pm 0.02$ vs. 3.09 $\pm 0.02)$ than cows without subclinical ketosis.

Prevalence of diseases based on category of BCS at 7 DIM was less $(P<0.01)$ for cows with BCS between 3.00 and 3.25 than for those with BCS $<3.00$ and those with BCS $>3.25$ (69.3 vs. 76.3 vs. $79.4 \%$, respectively). For clinical diseases only, prevalence was less $(P<0.01)$ for cows with BCS between 3.00 and 3.25, followed by those with BCS $>3.25$ and then by those with BCS $<3.00$ (31.3 vs. 35.6 vs. $45.1 \%$, respectively). Prevalence of calving problems (5.8 vs. $9.8 \%)$, metritis (3.3 vs. $8.8 \%$ ), clinical endometritis (12.3 vs. $20.1 \%$ ), mastitis (12.9 vs. $22.0 \%)$, and digestive problems $(2.0$ vs. $6.4 \%)$ were all less $(P<0.01)$ for cows with BCS between 3.00 and 3.25 than for those with BCS $<3.00$. For subclinical diseases only, prevalence was greater $(P$ $<0.01$ ) for cows with BCS $>3.25$ than for those with BCS between 3.00 and 3.25 and those with BCS $<3.00$ (68.0 vs. 56.5 vs. $59.4 \%$, respectively). Prevalence of elevated NEFA concentration and subclinical ketosis were greater $(P<0.01)$ for cows with BCS $>3.25$ (38.1 and $55.8 \%$ ) compared with those with BCS between 3.00 and 3.25 (18.4 and 36.4\%) and those with BCS $<3.00$ (15.8 and $26.7 \%$ ). For subclinical hypocalcemia, prevalence was less $(P<0.01)$ for cows with BCS between 3.00 and 3.25 (37.6\%), followed by cows with BCS $>3.25(42.9 \%)$ and then by cows with BCS $<3.00$ $(53.2 \%)$.

Average BCS at the time points evaluated and changes in BCS postpartum differed $(P<0.01)$ according to categorized BCS at 7 DIM. Cows calving with BCS $>3.25$ had greater $(P<0.01)$ BCS than those calving with BCS between 3.00 and 3.25 and those calving BCS $<3.00(3.33 \pm 0.02$ vs. $3.02 \pm 0.01$ vs. 2.80 \pm 0.01 , respectively). Nevertheless, cows calving with greater BCS experienced increased $(P<0.01)$ losses of body condition in the first 35 DIM. As BCS at calving increased from BCS $<3.00$ to BCS between 3.00 and 
Table 8. Serum concentrations of Ca and NEFA on d $7 \pm 3$ and BHBA on d $14 \pm 3$ according to prevalence of postpartum diseases

\begin{tabular}{|c|c|c|c|c|c|c|c|c|c|}
\hline \multirow[b]{2}{*}{ Health problem } & \multicolumn{3}{|c|}{$\mathrm{Ca}, \mathrm{m} M$} & \multicolumn{3}{|c|}{ NEFA, $m M$} & \multicolumn{3}{|c|}{$\mathrm{BHBA}, \mathrm{m} M$} \\
\hline & $\mathrm{No}^{1}$ & $\mathrm{Yes}^{2}$ & $P$-value & No & Yes & $P$-value & No & Yes & $P$-value \\
\hline \multicolumn{10}{|l|}{ Clinical disease } \\
\hline Calving problems & $2.15 \pm 0.01$ & $2.13 \pm 0.03$ & 0.57 & $0.41 \pm 0.02$ & $0.43 \pm 0.04$ & 0.88 & $0.98 \pm 0.05$ & $0.67 \pm 0.13$ & $<0.01$ \\
\hline Metritis & $2.15 \pm 0.01$ & $2.06 \pm 0.03$ & $<0.01$ & $0.40 \pm 0.02$ & $0.49 \pm 0.05$ & 0.02 & $0.95 \pm 0.05$ & $1.10 \pm 0.14$ & 0.73 \\
\hline Clinical endometritis & $2.15 \pm 0.01$ & $2.11 \pm 0.02$ & 0.04 & $0.41 \pm 0.02$ & $0.41 \pm 0.03$ & 0.80 & $0.96 \pm 0.05$ & $0.98 \pm 0.09$ & 0.90 \\
\hline Mastitis & $2.14 \pm 0.01$ & $2.16 \pm 0.02$ & 0.33 & $0.41 \pm 0.02$ & $0.43 \pm 0.03$ & 0.16 & $0.96 \pm 0.05$ & $0.96 \pm 0.09$ & 0.49 \\
\hline Respiratory problems & $2.15 \pm 0.01$ & $2.09 \pm 0.05$ & 0.35 & $0.41 \pm 0.02$ & $0.49 \pm 0.08$ & 0.17 & $0.97 \pm 0.05$ & $0.57 \pm 0.25$ & 0.45 \\
\hline Digestive problems & $2.15 \pm 0.01$ & $2.09 \pm 0.04$ & 0.22 & $0.41 \pm 0.02$ & $0.45 \pm 0.06$ & 0.87 & $0.96 \pm 0.05$ & $0.95 \pm 0.16$ & 0.90 \\
\hline Lameness & $2.15 \pm 0.01$ & $2.14 \pm 0.04$ & 0.95 & $0.41 \pm 0.02$ & $0.45 \pm 0.06$ & 0.68 & $0.97 \pm 0.05$ & $0.81 \pm 0.16$ & $<0.01$ \\
\hline \multicolumn{10}{|l|}{ Subclinical disease } \\
\hline Hypocalcemia & - & - & - & $0.36 \pm 0.02$ & $0.47 \pm 0.02$ & $<0.01$ & $0.89 \pm 0.06$ & $1.04 \pm 0.07$ & 0.05 \\
\hline Elevated NEFA concentration ${ }^{3}$ & $2.16 \pm 0.01$ & $2.08 \pm 0.02$ & $<0.01$ & $0.00+0.02$ & -0.02 & - & $0.79 \pm 0.04$ & $1.77 \pm 0.07$ & $<0.01$ \\
\hline Ketosis & $2.16 \pm 0.01$ & $2.11 \pm 0.01$ & $<0.01$ & $0.31 \pm 0.02$ & $0.63 \pm 0.02$ & $<0.01$ & - & - & - \\
\hline Subclinical endometritis ${ }^{4}$ & $2.17 \pm 0.16$ & $2.07 \pm 0.03$ & $<0.01$ & $0.49 \pm 0.02$ & $0.60 \pm 0.04$ & 0.01 & $1.24 \pm 0.07$ & $1.39 \pm 0.13$ & 0.27 \\
\hline
\end{tabular}

${ }^{1}$ No $=$ cow was not diagnosed with the respective clinical or subclinical disease

${ }^{2}$ Yes $=$ cow was diagnosed with the respective clinical or subclinical disease.

${ }^{3}$ Elevated NEFA concentration = serum NEFA concentration $\geq 0.70 \mathrm{~m} M$; subclinical ketosis was based on a serum BHBA concentration $\geq 0.96 \mathrm{~m} M$; subclinical hypocalcemia was based on a serum Ca concentration $\leq 2.14 \mathrm{~m} M$.

${ }^{4}$ Evaluated in cows from farm A only.

Table 9. Serum concentrations of Ca and NEFA on d $7 \pm 3$ and BHBA on d $14 \pm 3$ according to categorization of cows as estrous cyclic, pregnant, or having pregnancy loss BHBA, $\mathrm{m} M$

NEFA, $\mathrm{m} M$

$\mathrm{Ca}, \mathrm{m} M$

Fertility response

Yes $^{2} \quad P$-value

Yes

$P$-value

$0.49 \pm 0.04$

$0.40 \pm 0.02$

$2.16 \pm 0.0$

$2.14 \pm 0.01 \quad 2.16 \pm 0.01$

$<0.01$

0.34

$2.14 \pm 0.03$

0.55

$0.45 \pm 0.02$

$0.38 \pm 0.02$

$0.34 \pm 0.04$

0.02

0.02
$<0.01$

0.01

0.29

$0.38 \pm 0.02$

${ }^{1} \mathrm{No}=$ cow was not diagnosed as having the respective fertility response evaluated (estrous cyclic, pregnant, or pregnancy loss). 

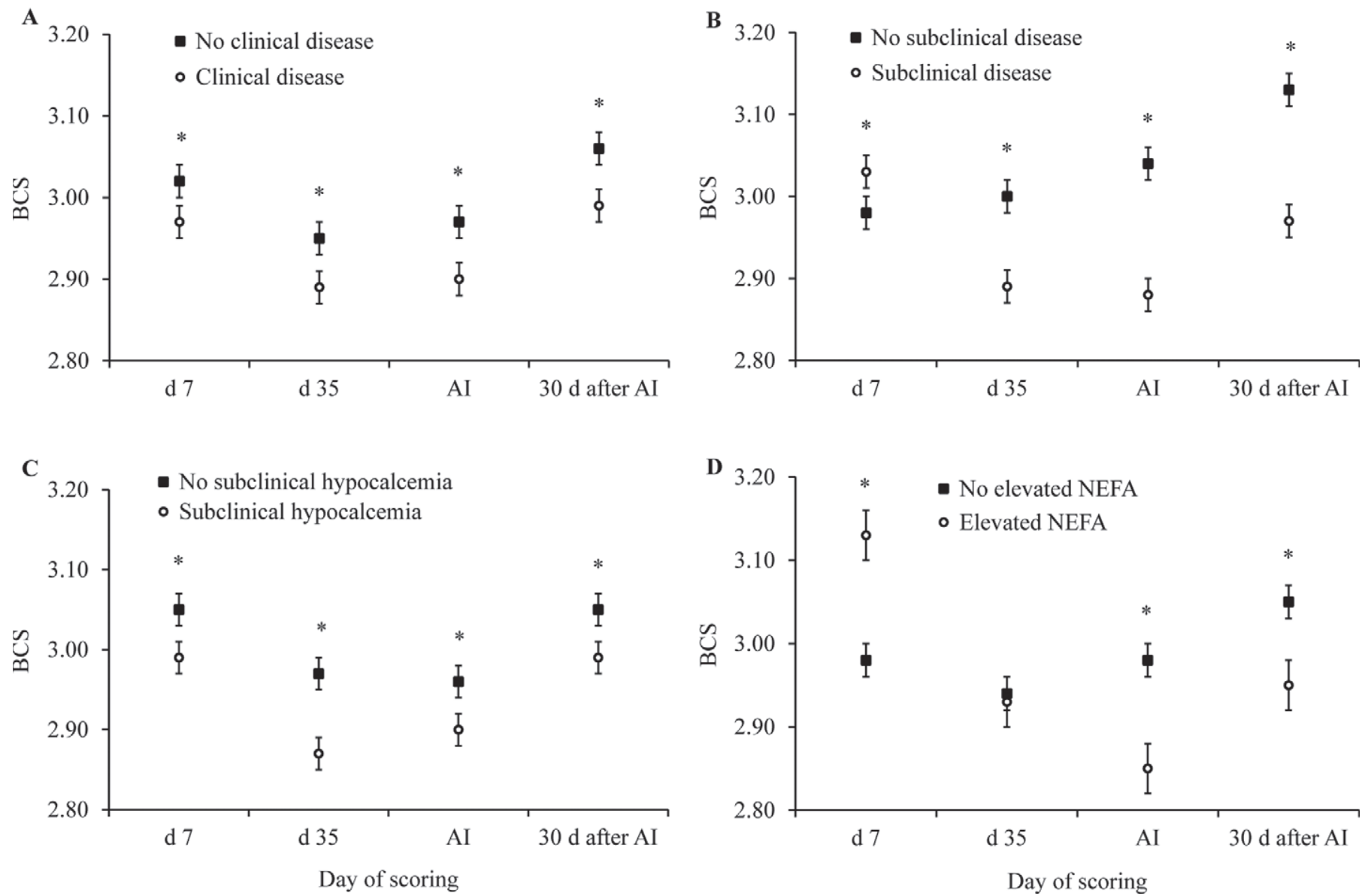

Figure 2. Body condition score at 7 and $35 \mathrm{~d}$ postpartum, on the day of AI, when cows averaged $86 \mathrm{~d}$ postpartum, and $30 \mathrm{~d}$ after AI, when cows averaged 116 d postpartum, according to prevalence of clinical diseases (A), subclinical diseases (B), subclinical hypocalcemia (Ca concentration $<2.14 \mathrm{~m} M ; \mathrm{C}$ ), and elevated NEFA concentration (NEFA concentration $\geq 0.70 \mathrm{~m} M ; \mathrm{D})$. * specifies significant effects $(P<0.05)$ of explanatory variable within day of scoring. Panel A: effects of disease: $P<0.01$, day of scoring: $P<0.01$, and interaction between disease and day of scoring: $P=0.71$. Panel B: effects of disease: $P<0.01$, day of scoring: $P<0.01$, and interaction between disease and day of scoring: $P$ $<0.01$. Panel C: effects of disease: $P<0.01$, day of scoring: $P<0.01$, and interaction between disease and day: $P=0.04$. Panel D: effects of disease: $P=0.35$, day of scoring: $P<0.01$, and interaction between disease and day of scoring: $P<0.01$. Error bars represent the SEM.

3.25 , and to BCS $>3.25$, so did the loss of body condition $(+0.08 \pm 0.02$ vs. $-0.11 \pm 0.01$ vs. $-0.38 \pm 0.02$, respectively). From 35 DIM to $30 \mathrm{~d}$ after AI, cows in all 3 categories of BCS at calving gained body condition $(P<0.01)$ : on average, $0.11 \pm 0.01,0.12 \pm 0.02$, and $0.11 \pm 0.03$ units for cows with BCS $<3.00$, BCS between 3.00 and 3.25 , and $\mathrm{BCS}>3.25$, respectively.

Yields of milk, 3.5\% FCM, and ECM differed $(P<$ $0.01)$ among breeds and were all greatest $(P<0.01)$ for Holsteins $(24.7 \pm 0.6,22.5 \pm 0.6$, and $22.3 \pm 0.6 \mathrm{~kg} / \mathrm{d})$, followed by crossbreds $(21.2 \pm 0.3,20.6 \pm 0.4$, and 20.5 $\pm 0.3 \mathrm{~kg} / \mathrm{d})$, and then Jerseys $(16.7 \pm 0.9,17.0 \pm 0.9$, and $17.0 \pm 0.9 \mathrm{~kg} / \mathrm{d})$.

\section{DISCUSSION}

This study characterizes the prevalence of clinical and subclinical periparturient diseases and their effects on reproduction of dairy cows in seasonally calving grazing farms. Compared with high-producing dairy cows in confinement, grazing dairy cows produce less milk but are generally considered more fertile and healthier (Washburn et al., 2002; McDougall, 2006). Nonetheless, the present study demonstrated that prevalences of clinical and subclinical health problems were relatively high in the 2 farms studied. Furthermore, despite the high fertility observed following first AI, cows diagnosed with either clinical or subclinical diseases had reduced estrous cyclicity on d 49 postpartum and pregnancy at first AI, and increased risk of pregnancy loss. These findings highlight the importance of having an adequate health program during the transition period in seasonally calving dairy herds.

Approximately $75 \%$ of all diseases in dairy cows are diagnosed in the first month of lactation (LeBlanc et al., 2006). Events related to calving and the transition 
period, such as dystocia and uterine diseases (McDougall, 2001; Sheldon et al., 2009), peripartum immune dysfunction (Kehrli et al., 1989; Hammon et al., 2006), endocrine and metabolic changes (Bauman and Currie, 1980), reductions in DMI and nutrient imbalance (Drackley, 1999), and contaminated environment (LeBlanc et al., 2006), are major risk factors leading to the occurrence of health problems. Therefore, minimization of such events is fundamental for obtaining adequate health and optimal performance in dairy cows.

Twenty-seven percent of the cows in the study did not experience any type of health problem and this subgroup of cows had excellent fertility. Nonetheless, the remaining $73 \%$ of cows with clinical or subclinical diseases, or both, had compromised resumption of estrous cyclicity and P/AI. Similar to our findings, Santos et al. (2010) observed a high prevalence of clinical diseases in high-producing cows in confinement farms, and cows with clinical diseases were less likely to be cyclic and become pregnant, and more likely to lose a pregnancy in the first $60 \mathrm{~d}$ of gestation. In the present study, fertility was further reduced in cows diagnosed with multiple health problems, clinical or subclinical, compared with those that experienced a single health problem. In addition to low $\mathrm{P} / \mathrm{AI}$, multiple clinical diseases also increased the incidence of pregnancy losses by gestation d 65. Despite maximal submission to AI with a timed AI program, lower $\mathrm{P} / \mathrm{AI}$ and higher pregnancy losses compromises pregnancy rate, which is crucial for seasonally calving herds, especially early in breeding season (McDougall, 2006, 2010).

Diseases have been linked with a delay in postpartum estrous cyclicity (Santos et al., 2010). In the current study, clinical and subclinical diseases were associated with greater prevalence of anovular cows at d 49 postpartum. Cows with elevated NEFA and those with subclinical hypocalcemia had increased prevalence of anovulation. A high serum NEFA concentration is an indicator of lipid mobilization (Drackley, 1999). Cows with excessive loss of body fat are usually under a more negative nutrient balance, which likely also affects $\mathrm{Ca}$ balance. In fact, serum concentrations of NEFA and Ca were negatively correlated, and increased NEFA and BHBA concentrations have been observed in cows with subclinical hypocalcemia (Martinez et al., 2012). These cows might have less DMI and greater nutrient output in milk, which are expected reduce serum Ca concentrations and increase lipomobilization.

In grazing farms, energy balance can be of great concern because of low DMI and the typically lesscaloric dense diets consumed by cows (Bargo et al., 2003; Kolver, 2003). Resumption of postpartum estrous cyclicity is directly linked with the nutritional status of the cow (Butler, 2003), and nutrient intake explains better energy balance than milk energy secretion (Santos et al., 2010). Although nutrient intake was not measured, cows with elevated NEFA concentrations were less likely to be cyclic and to become pregnant at the first AI. All cows in the current study were subjected to an ovulation synchronization program, which can override the negative effect of anovulation on insemination rate, but not on P/AI (Santos et al., 2009; McDougall, 2010). In fact, fertility of anovular cows was markedly compromised: approximately 25 to 30 fewer percentage units of $\mathrm{P} / \mathrm{AI}$ compared with cyclic herdmates.

Cows with subclinical hypocalcemia were more likely to develop metritis and clinical and subclinical endometritis than cows with normocalcemia. In fact, serum Ca concentrations were less in cows with uterine diseases. Store of cytosolic Ca in cows with clinical hypocalcemia is reduced, which compromises activation of leukocytes (Kimura et al., 2006). Martinez et al. (2012) demonstrated that cows with subclinical hypocalcemia had impaired neutrophil function and that the probability of metritis was directly related to a decline in serum Ca concentration early postpartum. Additionally, Hammon et al. (2006) reported that impaired neutrophil function and negative energy balance prepartum were associated with uterine diseases in early lactation. In fact, cows with metritis and subclinical endometritis in the current study had also greater concentrations of NEFA. Thus, Ca homeostasis and energy balance are interrelated and both affect immune cell function, which influence the susceptibility to clinical diseases and, consequently, compromise fertility. Also, changes in blood metabolites reflect changes in follicular fluid composition (Leroy et al., 2008), which could impair follicular steroidogenesis and oocyte developmental competence, compromising resumption of cyclicity and fertility.

In general, prevalence of metritis and clinical endometritis were relatively low, particularly compared with the prevalence reported for cows in confinement dairies (Dubuc et al., 2010; Santos et al., 2010; Chapinal et al., 2011). Nevertheless, diseases that affected the uterus had the greatest effect on P/AI. Indeed, metritis and clinical endometritis had additive effects, reducing $\mathrm{P} / \mathrm{AI}$ and resulting in the greatest pregnancy loss. McDougall (2001) reported that grazing cows with dystocia or retained fetal membranes had lower $\mathrm{P} /$ $\mathrm{AI}$ and slower pregnancy rate than unaffected herdmates. A comprehensive study with 2,793 grazing cows demonstrated that clinical endometritis affected $21.2 \%$ of the population and reduced reproductive efficiency during the breeding season (McDougall et al., 2007). In fact, after parturition, almost all cows have a uterus contaminated by a wide range of bacteria, and the development of uterine diseases depends on the ability of 
the local immune system to control bacterial growth (Sheldon et al., 2009). It is thought that bacteria and products of inflammation from the uterus influence ovarian follicular activity in early lactation (Sheldon et al., 2009), which compromises resumption of ovulation. Also, uterine inflammation is likely to damage the endometrium and the uterine glands, which are critical for proper establishment and maintenance of pregnancy.

Body condition reflects the amount of subcutaneous body fat of cows (Ferguson et al., 1994), and cows usually are scored during the dry and early lactation periods because of links with subsequent performance. Prevalence of diseases was associated with BCS at $7 \mathrm{~d}$ postpartum. Cows with BCS $<3.00$ were more likely to develop clinical diseases and subclinical hypocalcemia, whereas those with BCS $>3.25$ were more likely to have elevated NEFA concentration and subclinical ketosis. Body condition in the first week postpartum also resulted in differences in the shape of the BCS profile, especially the changes in BCS in the first $35 \mathrm{~d}$ postpartum. Cows that experienced greater losses in BCS early postpartum are likely to have an extended anovulatory period, decreased $\mathrm{P} / \mathrm{AI}$, and increased risk of pregnancy loss (Santos et al., 2009). Based on the proportion cows with no diagnosis of clinical or subclinical diseases, it seems that the ideal BCS for grazing cows at calving is between 3.00 and 3.25. These cows experienced minor BCS loss in the first 35 DIM and had the least prevalence of clinical and subclinical diseases. Thus, managing prepartum diet and targeting cows to an ideal BCS at calving (3.00 to 3.25) should minimize occurrence of health problems and improve productive and reproductive performance.

It is important to emphasize that cows in this study were of North American genetics, which, in general, partition more nutrients toward production at the expense of body reserves compared with New Zealand genetics (Lucy et al., 2009). Nonetheless, there were 3 distinct genetic groups with different yields of ECM: Holsteins with the highest, crossbreds intermediate, and Jerseys with the lowest yield. Interestingly, no major differences in the prevalence of diseases were observed among them. Also, P/AI did not differ according to breed, although other studies have documented earlier resumption of estrous cyclicity and better $\mathrm{P} / \mathrm{AI}$ in crossbred cows (Ribeiro et al., 2011, 2012). Therefore, under the management imposed in the studied farms, breed of the cow had little influence on the susceptibility to postpartum diseases.

\section{CONCLUSIONS}

Prevalence of clinical and subclinical health problems in the 2 grazing herds studied was high and cows diag- nosed with diseases had reduced prevalence of estrous cyclicity at d 49 postpartum, reduced $\mathrm{P} / \mathrm{AI}$ on d 30 and 65 after the first insemination, and increased the risk of pregnancy loss. Fertility declined further with diagnosis of multiple clinical and (or) subclinical diseases. The decline in fertility was caused by reduced $\mathrm{P} / \mathrm{AI}$ and increased pregnancy loss. Clinical uterine diseases seem to have had the greatest effect on P/AI, and cows having both metritis and clinical endometritis suffered more than those having either one of the two problems. Serum concentrations of Ca and NEFA in the first 10 d postpartum were negatively correlated and highly associated with the development of uterine diseases. In summary, although pregnancy to first postpartum AI averaged $62 \%$ for all cows on d 30 after insemination, the results from this study clearly demonstrated that periparturient clinical and subclinical diseases were prevalent in grazing dairy cows and delayed estrous cyclicity, reduced P/AI, and increased the risk of pregnancy loss. Management of grazing cows to optimize fertility should focus on reducing periparturient diseases and lipid mobilization, and on improving $\mathrm{Ca}$ homeostasis. Targeting cows to an ideal BCS at calving is one of practical management activities to minimize these problems.

\section{ACKNOWLEDGMENTS}

The authors thank the owner, Ron St. John, and the staff of Piedmont and Watson Dairies (Trenton, FL) for use of their cows and facilities. The assistance of Nilo Francisco, Pat Cilo Cilo, and Cliff Reindl is greatly appreciated. Our appreciation is extended to Carlos Risco and Fiona Maunsell in the College of Veterinary Medicine at the University of Florida (Gainesville) for use of their laboratory facilities and contributions to the manuscript.

\section{REFERENCES}

Bargo, F., L. D. Muller, E. S. Kolver, and J. E. Delahoy. 2003. Invited review: Production and digestion of supplemented dairy cows on pasture. J. Dairy Sci. 86:1-42.

Bauman, D. E., and W. B. Currie. 1980. Partitioning of nutrients during pregnancy and lactation: A review of mechanisms involving homeostasis and homeorhesis. J. Dairy Sci. 63:1514-1529.

Brownlie, T. S., A. M. Weir, I. Tarbotton, J. M. Morton, C. Heuer, and S. McDougall. 2011. Reproductive management of dairy herds in New Zealand: Attitudes, priorities and constraints perceived by farmers managing seasonal-calving, pasture-based herds in four regions. N. Z. Vet. J. 59:28-39.

Butler, W. R. 2003. Energy balance relationships with follicular development, ovulation and fertility in postpartum dairy cows. Livest. Prod. Sci. 83:211-218.

Chapinal, N., M. Carson, T. F. Duffield, M. Capel, S. Godden, M. Overton, J. E. P. Santos, and S. J. LeBlanc. 2011. The evaluation of serum metabolites for the prediction of clinical disease during the transition period. J. Dairy Sci. 94:4897-4903. 
Drackley, J. K. 1999. Biology of dairy cows during the transition period: The final frontier? J. Dairy Sci. 82:2259-2273.

Dubuc, J., T. F. Duffield, K. E. Leslie, J. S. Walton, and S. J. LeBlanc. 2010. Risk factors for postpartum uterine diseases in dairy cows. J. Dairy Sci. 93:5764-5771.

Ferguson, J. D., D. T. Galligan, and N. Thomsen. 1994. Principal descriptors of body condition score in Holstein cows. J. Dairy Sci. 77:2695-2703.

Gilbert, R. O., S. T. Shin, C. L. Guard, H. N. Erb, and M. Frajblat. 2005. Prevalence of endometritis and its effects on reproductive performance of dairy cows. Theriogenology 64:1879-1888.

Hammon, D. S., I. M. Evjen, T. R. Dhiman, J. P. Goff, and J. L. Walters. 2006. Neutrophil function and energy status in Holstein cows with uterine health disorders. Vet. Immunol. Immunopathol. 113:21-29.

Horan, B., J. F. Mee, M. Rath, P. O'Connor, and P. Dillon. 2004. The effect of strain of Holstein-Friesian cow and feeding system on reproductive performance in seasonal-calving milk production systems. Anim. Sci. 79:453-467.

Johnson, M. M., and J. P. Peters. 1993. Technical note: An improved method to quantify nonesterified fatty acids in bovine plasma. J. Anim. Sci. 71:753-756.

Kehrli, M. E., B. J. Nonnecke, and J. A. Roth. 1989. Alterations in bovine PMN function during the periparturient period. Am. J. Vet. Res. 50:207-214.

Kimura, K., T. A. Reinhardt, and J. P. Goff. 2006. Parturition and hypocalcemia blunts calcium signals in immune cells of dairy cattle. J. Dairy Sci. 89:2588-2595.

Kolver, E. S. 2003. Nutritional limitations to increased production on pasture-based systems. Proc. Nutr. Soc. 62:291-300.

LeBlanc, S. J., K. D. Lissemore, D. F. Kelton, T. F. Duffield, and K. E. Leslie. 2006. Major advances in disease prevention in dairy cattle. J. Dairy Sci. 89:1267-1279.

Leroy, J. L. M. R., T. Vanholder, A. T. M. Van Knegsel, I. GarciaIspierto, and P. E. J. Bols. 2008. Nutrient prioritization in dairy cows early postpartum: Mismatch between metabolism and fertility? Reprod. Domest. Anim. 43:96-103.

Lucy, M. C., G. A. Verkerk, B. E. Whyte, K. A. Macdonald, L. Burton, R. T. Cursons, J. R. Roche, and C. W. Holmes. 2009. Somatotropic axis components and nutrient partitioning in genetically diverse dairy cows managed under different feed allowances in a pasture system. J. Dairy Sci. 92:526-539.

Martinez, N., C. A. Risco, F. S. Lima, R. S. Bisinotto, L. F. Greco, E. S. Ribeiro, F. Maunsell, K. Galvão, and J. E. P. Santos. 2012. Evaluation of peripartal calcium status, energetic profile and neutrophil function in dairy cows at low or high risk of developing uterine disease. J. Dairy Sci. 95:7158-7172.

McDougall, S. 2001. Effects of periparturient diseases and conditions on the reproductive performance of New Zealand dairy cows. N. Z. Vet. J. 49:60-67.
McDougall, S. 2006. Reproduction performance and management of dairy cattle. J. Reprod. Dev. 52:185-194.

McDougall, S. 2010. Comparison of diagnostic approaches, and a costbenefit analysis of different diagnostic approaches and treatments of anoestrous dairy cows. N. Z. Vet. J. 58:81-89.

McDougall, S., R. Macaulay, and C. Compton. 2007. Association between endometritis diagnosis using a novel intravaginal device and reproductive performance in dairy cattle. Anim. Reprod. Sci 99:9-23.

Morton, J. M. 2010. Interrelationships between herd-level reproductive performance measures based on intervals from initiation of the breeding program in year-round and seasonal calving dairy herds. J. Dairy Sci. 93:901-910.

Ospina, P. A., D. V. Nydam, T. Stokol, and T. R. Overton. 2010. Evaluation of nonesterified fatty acids and beta-hydroxybutyrate in transition dairy cattle in the northeastern United States: Critical thresholds for prediction of clinical diseases. J. Dairy Sci. 93:546-554.

Pedernera, M., S. C. García, A. Horagadoga, I. Barchia, and W. J. Fulkerson. 2008. Energy balance and reproduction on dairy cows fed to achieve low or high milk production on a pasture-based system. J. Dairy Sci. 91:3896-3907.

Rhodes, F. M., S. McDougall, C. R. Burke, G. A. Verkerk, and K. L. Macmillan. 2003. Treatment of cows with an extended postpartum anestrous interval. J. Dairy Sci. 86:1876-1894.

Ribeiro, E. S., R. L. A. Cerri, R. S. Bisinotto, F. S. Lima, F. T. Silvestre, M. G. Favoreto, L. F. Greco, W. W. Thatcher, and J. E. P. Santos. 2011. Reproductive performance of grazing dairy cows following presynchronization and resynchronization protocols. J. Dairy Sci. 94:4984-4996.

Ribeiro, E. S., A. P. A. Monteiro, F. S. Lima, H. Ayres, R. S. Bisinotto, M. Favoreto, L. F. Greco, R. S. Marsola, W. W. Thatcher, and J. E. P. Santos. 2012. Effects of presynchronization and length of proestrus on fertility of grazing dairy cows subjected to a 5 -day timed artificial insemination protocol. J. Dairy Sci. 95:2513-2522.

Santos, J. E. P., R. S. Bisinotto, E. S. Ribeiro, F. S. Lima, L. F. Greco C. R. Staples, and W. W. Thatcher. 2010. Applying nutrition and physiology to improve reproduction in dairy cattle. Soc. Reprod. Fertil. Suppl. 67:387-403

Santos, J. E. P., H. M. Rutigliano, and M. F. Sá Filho. 2009. Risk factors for resumption of postpartum estrous cycles and embryonic survival in lactating dairy cows. Anim. Reprod. Sci. 110:207-221.

Sheldon, I. M.. J. Cronin, L. Goetze, G. Donofrio, and H. Schuberth. 2009. Defining postpartum uterine disease and the mechanisms of infection and immunity in the female reproductive tract in cattle. Biol. Reprod. 81:1025-1032.

Washburn, S. P., S. L. White, J. T. Green Jr., and G. A. Benson. 2002. Reproduction, mastitis and body condition of seasonally calved Holstein and Jersey cows in confinement or pasture systems. J. Dairy Sci. 85:105-111. 